\title{
Prevention of atherosclerotic cardiovascular disease is possible but poorly put into practice
}

\author{
Guy G. De Backer \\ Department of Public Health and Primary Care, Ghent University, Ghent, Belgium
}

\author{
RELATED ARTICLE \\ by Pająk et al, \\ see p. 429
}

Correspondence to: Guy G. De Backer, Department of Public Health and Primary Care, Ghent University, Ghent University Hospital, C. Heymanslaan 10, B 9000 Ghent, Belgium, phone: +3292826970, email: guy.debacker@ugent.be Received: April 14, 2020. Accepted: April 15, 2020. Published online: May 25, 2020. Kardiol Pol. 2020; 78 (5): 383-385 doi:10.33963/KP.15382 Copyright by the Author(s), 2020
Atherosclerotic cardiovascular disease (ASCVD) is still a major cause of premature mortality, disability-adjusted life years, and increasing health care costs worldwide. The dynamics of the epidemic of ASCVD have been and still are very different between countries, and within a country between regions. This has been well documented in the World Health Organization MONICA (Multinational Monitoring of Trends and Determinants in Cardiovascular Disease) project $^{1}$ in which results from 2 regions from Poland were included.

Research units from Poland did also participate in the World Health Organization European Collaborative Group trial in which it was demonstrated that in middle-aged men, lifestyle changes were effective for the prevention of coronary heart disease (CHD) to the extent that they were accepted and put into practice. ${ }^{2}$

The potential of the primary prevention of ASCVD has been demonstrated in various randomized controlled trials and in cardiovascular community projects. Some of these projects such as the North Karelia Project ${ }^{3}$ resulted in impressive health benefits while other were less successful leading to criticism and debates. ${ }^{4,5}$ However, we need to remember that in intervention studies, differences in the incidence of ASCVD between intervention and control groups can only be expected to the extent to which the cardiovascular risk profile has been influenced differently between these groups. ${ }^{5}$

The potential of prevention of ASCVD has been summarized in guidelines by joint task forces of the European Society of Cardiology and other scientific societies from 1994 onwards with the last update in $2016 .{ }^{6}$ These guidelines on cardiovascular disease prevention in clinical practice contain numerous recommendations regarding lifestyle adaptations and optimal control of the major cardiovascular risk factors. Surveys have been conducted to evaluate how well these guidelines are implemented in daily practice; among them the EUROASPIRE (European Action on Secondary and Primary Prevention Through Intervention to Reduce Events) surveys, launched in 1995, with Poland participating from the EUROASPIRE II survey in 1999 to 2000 until EUROASPIRE V in 2016 to 2017.7,8 In these surveys, it was demonstrated in patients with CHD and in those at high cardiovascular risk, that lifestyle adaptations and risk factor control are poorly implemented when compared with what is recommended in the guidelines. ${ }^{7,8}$ This was confirmed in a large group of coronary patients from 4 geographical areas in Poland (POLASPIRE). ${ }^{9}$

Over the last 2 decades, some improvements have been made, but the majority of targets are not reached especially when it comes to lifestyle adaptations.

The barriers to better results have to do with factors related to patients, practitioners, and to healthcare systems. Once identified, they should be tackled with strategies that should be evaluated as to their effectiveness, safety, and cost-efficiency. Innovative management programs were developed and tested, among them the EUROACTION (Nurse-coordinated Multidisciplinary, Family-based Cardiovascular Disease Prevention Program) program. It has been tested at the international level and the results were promising. ${ }^{10}$ In this issue of Kardiologia Polska (Kardiol Pol, Polish Heart Journal), the results are presented from the Polish component to the EUROACTION; in addition, a long-term mortality follow-up is available in that study. ${ }^{11}$ With a structured, nurse-led, comprehensive, 
primary and secondary prevention program, improvements were achieved in lifestyle and in risk factor control using a paired, cluster-randomized controlled trial design. These improvements were associated with a reduction in mortality. Although these results are encouraging, there is scope for improvement, especially when considering the results after 12 years when most of what had been achieved in the beginning was lost on the exception of some dietary habits. There is a need for a continuous support by a network of health professionals with expertise in smoking cessation techniques, exercise prescription, and dietary counselling. Physicians play a crucial role in drug prescription to control the major cardiovascular risk factors. It is surprising and alarming to see that among the patients with ASCVD in the intervention group of the Polish component to the EUROACTION, only $49 \%$ and $55 \%$ were on respectively antiplatelet agents and statins at 12-year follow-up; the advantage of these drugs for secondary prevention of ASCVD has been well documented. In order to close the gap between the potential of ASCVD prevention and the implementation of that knowledge into practice, there is a need for a sustainable interdisciplinary intervention not only during a short time period but integrated in a continuous follow-up of patients and high-risk subjects. Prevention of ASCVD should be implemented at all levels of society and in all healthcare settings. Healthcare workers should consider health promotion and preventive cardiology as a crucial part of their professional responsibilities and should be well trained in monitoring and advising adherence to healthy lifestyles and to long-term drug therapies. Increasing the health literacy of patients is another major challenge that can reinforce the patient-doctor relationship allowing the patient to participate in informed decision making.

The EUROACTION is not the only trial in which the effects of a nurse-coordinated preventive cardiology program was tested. In the Netherlands, advanced practice nurses did achieve results equal or better than general practitioners for the management of cardiovascular risk factors. ${ }^{12}$ In the RESPONSE (Randomised Evaluation of Secondary Prevention by Outpatient Nurse Specialists) trial among patients after an acute coronary syndrome, a better control of cardiovascular risk factors was observed in the intervention group with also fewer readmissions..$^{13}$ Maintaining healthy lifestyle habits may be a problem in many patients. Therefore, longer-term support for adherence may be needed. In the GOSPEL (Global Secondary Prevention Strategies to Limit Event Recurrence After MI) trial in patients after an acute myocardial infarction, a multifactorial intervention following a cardiac rehabilitation program was tested over a 3-year period. Compared with usual care, the intervention group had improved healthy lifestyle habits and risk factor control maintained throughout the study period and the intervention was associated with less recurrent cardiovascular events. ${ }^{14}$ In other projects conducted in France, China, Spain, Brazil, Australia, and New-Zealand, nurse-led models, developed in an interdisciplinary way with other health care professionals, have shown to be effective in improving the implementation of guidelines on ASCVD prevention. ${ }^{15}$

In conclusion, there is considerable potential to prevent ASCVD through effective lifestyle interventions and a rigorous control of dyslipidemia, arterial hypertension, and dysglycemia in patients with ASCVD and in those at high cardiovascular risk. Having identified the barriers to a better implementation of evidence-based guidelines, one should overcome them using interdisciplinary intervention programs embedded in various healthcare facilities with a long-term regular follow-up.

\section{ARTICLE INFORMATION}

DISCLAIMER The opinions expressed by the author are not necessarily those of the journal editors, Polish Cardiac Society, or publisher.

CONFLICT OF INTEREST None declared.

OPEN ACCESS This is an Open Access article distributed under the terms of the Creative Commons Attribution-NonCommercial-NoDerivatives 4.0 International License (CC BY-NC-ND 4.0), allowing third parties to download articles and share them with others, provided the original work is properly cited, not changed in any way, distributed under the same license, and used for noncommercial purposes only. For commercial use, please contact the journal office at kardiologiapolska@ptkardio.pl.

HOW TO CITE De Backer GG. Prevention of atherosclerotic cardiovascular disease is possible but poorly put into practice. Kardiol Pol. 2020; 78: 383-385. doi:10.33963/KP.15382

\section{REFERENCES}

1 Tunstall-Pedoe H, ed. MONICA monograph and multimedia sourcebook. Geneva: World Health Organization; 2003.

2 World Health Organization European Collaborative Group. European Collaborative trial of multifactorial prevention of coronary heart disease: final report of the 6-year results. Lancet. 1986; 1: 869-872.

3 Puska P, Vartiainen E, Tuomilehto J, et al. Changes in premature deaths in Finland: successful long-term prevention of cardiovascular disease. B World Health Organ. 1998; 76: 419-425.

4 Ebrahim S. Chronic diseases and calls to action. Int J Epidemiol 2008; 37: 225-230. 5 De Backer G, Kornitzer M. Chronic diseases and calls to action. Int J Epidemiol. 2010; 39: 310-311.

6 Piepoli MF, Hoes AW, Agewall S, et al. 2016 European guidelines on cardiovascular disease prevention in clinical practice. The Sixth Joint Task Force of the European Society of Cardiology and Other Societies on Cardiovascular Disease Prevention in Clinical Practice. Eur Heart J. 2016; 37: 2315-2381.

7 Kotseva K, De Backer G, De Bacquer D, et al. on behalf of the EUROASPIRE Investigators. Lifestyles and impact on cardiovascular risk factor control in coronary patients across 27 countries: Results from the European Society of Cardiology EUROASPIRE V survey. Eur J Prev Cardiol. 2019; 26: 824-835.

8 Kotseva K, De Backer G, De Bacquer D, et al. Primary prevention efforts are poorly developed in people at high cardiovascular risk: a report from the European Society of Cardiology EURObservational Research Programme EUROASPIRE V survey in 16 European countries. Eur J Prev Cardiol. 2020 Mar 20. [Epub ahead of print]. 9 Haberka M, Jankowski P, Kosior DA, et al. Treatment goal attainment for secondary prevention in coronary patients with and without diabetes mellitus - Polish multicenter study POLASPIRE. Arch Med Sci. 2020 Jan 23. [Epub ahead of print].

10 Wood DA, Kotseva K, Connolly S, et al. Nurse-coordinated multidisciplinary, family-based cardiovascular disease prevention programme (EUROACTION) for patients with coronary heart disease and asymptomatic individuals at high risk of cardiovascular disease: a paired, cluster-randomised controlled trial. Lancet. 2008; 371: 1999-2012.

11 Pająk A, Wolfshaut-Wolak R, Doryńska A, et al. Longitudinal effects of a nurse-managed comprehensive cardiovascular disease prevention program for hospitalized coronary heart disease patients and primary care high-risk patients. Kardiol Pol. 2020; 78: 429-437. 
12 Voogdt-Pruis HR, Beusmans GH, Gorgels AP, et al. Effectiveness of nurse-delivered cardiovascular risk management in primary care: a randomised trial. $\mathrm{Br}$ J Gen Pract. 2010; 60: 40-46.

13 Jorstad HT, von Birgelen C, Alings AM, et al. Effect of a nurse-coordinated prevention programme on cardiovascular risk after an acute coronary syndrome: main results of the RESPONSE randomised trial. Heart. 2013; 99: 1421-1430.

14 Giannuzzi P, Temporelli PL, Marchioli R, et al. Global secondary prevention strategies to limit event recurrence after myocardial infarction: results of the GOS-

PEL study, a multicenter, randomized controlled trial from the Italian Cardiac Rehabilitation Network. Arch Intern Med. 2008; 168: 2194-2204.

15 Jennings C, Astin F. A multidisciplinary approach to prevention. Eur J Prev Cardiol. 2017; 24: 77-87. 